\title{
Design and Construction of a Cycle with Power Generator Resistance as Load for Aerobic Exercise
}

\section{Ominyi Daniel Sunday, Amah Alexander Nwabueze, Ahemen Iorkya, Agada Inikpi Ojochenemi}

Department of Physics, University of Agriculture, Makurdi, Nigeria

\section{Email address:}

sundaydaniel54@yahoo.co.uk (O. D. Sunday)

\section{To cite this article:}

Ominyi Daniel Sunday, Amah Alexander Nwabueze, Ahemen Iorkya, Agada Inikpi Ojochenemi. Design and Construction of a Cycle with Power Generator Resistance as Load for Aerobic Exercise. Advances in Bioscience and Bioengineering. Vol. 5, No. 4, 2017 , pp. 56-62. doi: $10.11648 /$ j.abb.20170504.12

Received: April 25, 2017; Accepted: May 18, 2017; Published: October 19, 2017

\begin{abstract}
This work was concerned with the design and construction of an exercise cycle with power generator resistance as load for aerobic exercise. The cycle was designed based on the operational requirements of the cycle. The structure support base was constructed using the electric arc welding technique, while the structure frame parts were assembled together on the base support with the aid of bolt and nut joint technique. The generator was placed in contact with cycle wheel and its output terminals connected to a wet cell battery. An ergo-metric experiment was carried out using the cycle with a user weighing 71.6 $\mathrm{kg}$. The rider pedaled for exercise uninterruptedly for 10 minutes at the lowest speed of $72 \mathrm{rpm}$. The output voltage and current of the power generator were then read using multi-meter. The values were used to evaluate the electromagnetic resistance developed in the rotating armature of the power generator using relevant equations. The relationship between the resistance developed and other performance parameters were also identified and established. The experiment was repeated at various speeds and the corresponding resistance identified. These results collected were tabulated and their analysis with other measuring pairs established. The analysis shows that: the performance parameters varied directly proportional with the electromagnetic resistance; this validate the variability of the resistance mechanism. The exercise efficiency at various speeds does not vary distinctly from $51 \%$; this indicates that the pedaling speed of $72 \mathrm{rpm}$ is appropriate for exercise using this cycle. The total calories burnt $\left(671.1 \mathrm{~K}_{\text {cal }}\right)$ conform to the acceptable standard range $\left(70 \mathrm{~K}_{\text {cal }}-1500 \mathrm{~K}_{\text {cal }}\right)$ per day; it therefore validates the function of this exercise device as appropriate for aerobic exercise.
\end{abstract}

Keywords: Exercise Cycle, Power Generator, Electromagnetic Resistance, Wet-Cell Battery, Calorie Burnt

\section{Introduction}

This work is concern with the design and construction of a stationary cycle for aerobic exercise. Physical exercises on stationary machine require that exercise resistance be applied in opposite direction to the user's applied force from a neutral position [7]. In this work, an electric generator was used to develop electromagnetic torque (Counter torque) in the magnetic field of the generator when the output current is connected to a Battery (load). The counter torque acts as resistance or break against the rotation of the armature as well as the wheel in contact with the armature pulley. The wheel in turn resists the user's applied torque on the pedal.

Based on stationary exercise technology, other identified methods of developing resistance on stationary exercise bicycle includes the use of; friction rollers device which stimulate rolling resistance, wind on fan device which stimulates aerodynamic resistance and hydraulic fluid device which stimulates gradient resistance. It is known that variation of resistance in these methods interrupt the exercise process [8]. This method in this work is advantageous as the variable resistance developed during exercise does not interrupt the exercise process and the energy used is converted to electrical energy and stored in a battery for flexible uses.

Resistance exercise have been recommended as the best form of exercise for quick calorie burnt [4], body building, and athletic training [6] and have been recommended as a great natural medical tool [13]. Early versions of machines used for such exercise employed the free weights and conventional weight equipment that stimulates external 
resistance during exercise, but such method encountered several set back due to accidents witness by the users ${ }^{[2]}$. Researchers however recommended Machine-based equipment as safer and convenience exercise device compared to other more complex free weight equipment [12].

Some existing resistance sources use on stationary bicycle include friction rollers mechanism, hydraulic fluid mechanism, fan blade mechanism. Such devices though have certain limitations but do work quit well [11]. It is therefore obvious that the research to develop better exercise resistance is endless.

The specific objectives of this work are; i. design a suitable stationary exercise cycle ii. construct the cycle iii. place an electric generator rotor in contact with the bicycle wheel iv. connect the current to a battery v. capture the variation of resistance develop with other performance parameters using the method of statistical trend analysis.

\section{Devices and Methods}

\subsection{Devices}

The materials selected for the construction of the exercise cycle include:

Galvanized mild steel $[(0.38 \mathrm{M}, 0.013 \mathrm{M}$ diameter $)$ for frame support], a pair of bicycle cranks $(0.205 \mathrm{M})$, a pair of bicycle pedals, a bicycle sprocket, a bicycle roller chain, a bicycle tyre (41 cm diameter), a bicycle seat, a $12 \mathrm{~V}$ automobile generator, a $6 \mathrm{~V}$ wet cell battery.

\subsection{The Design of the Stationary Resistance Exercise Cycle}

The design structure of the stationary resistance exercise cycle is as shown in Figure 1.

Note: all measurements are in centimeter $(\mathrm{cm})$.

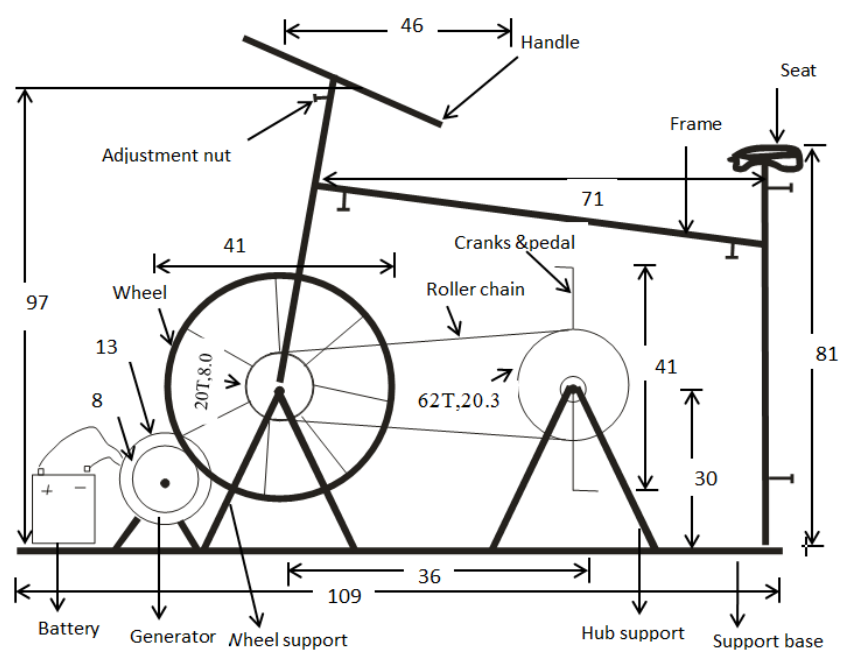

Figure 1. Design of the Aerobic Exercise cycle.

\subsection{Method of Data Collection}

Figure 2 shows a rider of weight $71.6 \mathrm{~kg}$ mounted on the exercise cycle. The rider cycles uninterruptedly for 10 minutes. His lowest cycling speed [revolution per minutes $\left(\mathrm{rpm}_{\mathrm{c}}\right.$ was $72 \mathrm{rpm}$. The attained speed for the rotor was designated as $\mathrm{rpm}_{\mathrm{r}}$. A multi-meter was connected to the output terminals of the generator to measure the output voltage and current and the readings were $6.3 \mathrm{~V}$ and $0.87 \mathrm{~A}$ respectively. The battery charged level was measured using the hydrometer and it read 1.02. The measured data were used to calculate other performing parameters like rotor speed, applied torque, counter torque and exercise efficiency.

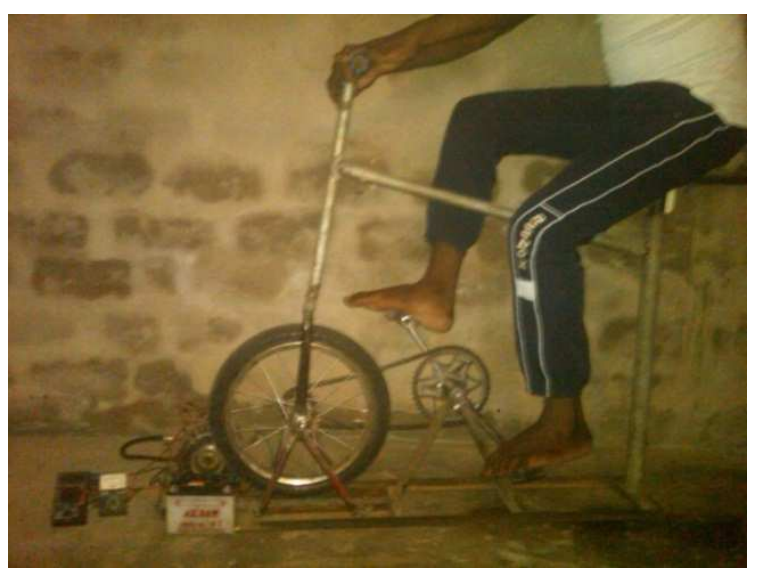

Figure 2. Picture of the Exercise Cycle with the Rider.

The designed structural evaluated was carried out to ensure safety and avoid failure during operation.

The maximum allowable load on the beam $\mathrm{F}$ can thus be obtained from the equation below;

$$
E=\frac{Y F L}{2}
$$

Where: $\mathrm{E}=$ Young's Modulus of Elasticity, $\mathrm{Y}=$ perpendicular distance from load point, $\mathrm{L}=$ length of the beam, $\mathrm{F}$ is the allowed force or load, 2 is the constant safety factor assumed for beam.

$$
\text { Hence, } F=\frac{2 E}{Y L}=1427.12 \mathrm{~N}=142.7 \mathrm{~kg}
$$

A bending moment is the reaction induced in a structural element when an external force or moment is applied to the element causing the element to bend [10].

Bending moment $(\mathrm{M})$ on the beam is usually expressed as in equation below;

$$
\mathrm{M}=\frac{F a b}{Y}=\frac{F L}{Y}=192.04 \mathrm{Kg}
$$

The evaluation of transmission chain was determined to avoid failure during operation. Chain must contain even integer number of links and hence cannot pick an arbitrary centre distance and chain pitch.

Nearest chain lengths ( $\mathrm{L}$ in pitches) is given by

$$
\mathrm{L}=\frac{N_{1}+N_{2}}{2}+\frac{2 C_{C}}{P}+\frac{P\left(N_{1}-N_{2}\right)}{4 C_{C} \pi^{2}}
$$

Where $\mathrm{N}_{1}$ and $\mathrm{N}_{2}$ are the numbers of teeth on the sprockets respectively, $\mathrm{p}$ is the chain pitch, $\mathrm{C}_{\mathrm{c}}$ is the contemplated center. Therefore $\mathrm{L}=136.03 \mathrm{~cm}$

The result of which should be rounded up to the next even 
number to calculate the actual center separation, $\mathrm{C}_{\mathrm{A}}{ }^{[14]}$.

The actual centre distance is thus given as;

Hence, $\mathrm{L}=138 \mathrm{~cm}$

$$
\mathrm{C}_{\mathrm{A}}=\frac{P}{8}\left[2 L-\left(N_{1}+N_{2}\right)+\sqrt{\left.\left[2 L-\left(N_{1}+N_{2}\right)\right] 2-\frac{\pi}{3.88}\left(N_{1}-N_{2}\right) 2\right]}\right.
$$

Hence, $\mathrm{C}_{\mathrm{A}}=35.796 \mathrm{~cm} \approx 36 \mathrm{~cm}$

With the lowest pedaling speed of $72 \mathrm{rpm}_{\mathrm{c}}$, the rotor speed was calculated as;

$$
d_{1} n_{1}=d_{2} n_{2}
$$

Where; $\mathrm{d}_{1}, \mathrm{n}_{1}$ is the wheel diameter $(\mathrm{cm})$ and speed $(\mathrm{rpm})$ respectively

$\mathrm{d}_{2}, \mathrm{n}_{2}$ is the rotor pulley diameter $(\mathrm{cm})$ and speed $(\mathrm{rpm})$ respectively

$$
\mathrm{d}_{1}=41, \mathrm{n}_{1}=72, \mathrm{~d}_{2}=8
$$

hence, $n_{2}=\frac{d_{1} n_{1}}{d_{2}}=\frac{41 \times 72}{8}=369 \mathrm{rpm}$

Figure 3 shows the simple basic circuit diagram of the rotor generator as it turns and develop electromagnetic torque during the exercise.

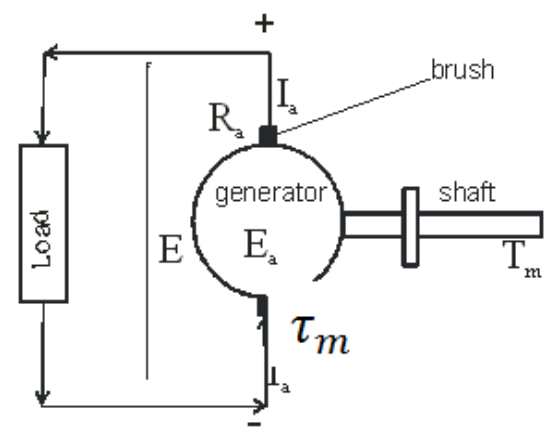

Figure 3. A Simple Generator Circuit Diagram.

$\mathrm{E}$ is the output EMF of the generator, $\mathrm{E}_{\mathrm{a}}$ is the induced EMF in the armature, $I_{a}$ is the armature current, $R_{a}$ is the armature resistance, $\tau_{m}$ is the applied external torque.

Torque $\left(\tau_{m}\right)$ is applied on the shaft, the armature then rotates in the magnetic field with angular speed ' $\omega$ '

The torque applied is given as;

$$
\tau_{m}=\frac{60 P}{2 \pi N}
$$

Where $\mathrm{N}$ is the armature rotating speed in $\mathrm{rpm}, \mathrm{P}$ is the armature output power.

The number of revolution per second of the armature disc is $\frac{N}{60}$

The speed in revolution per minute $\mathrm{N}$, is then related to the angular speed $\omega$ by

$$
\omega=\frac{2 \pi N}{60}
$$

where $N=n_{2}$

$$
\therefore \omega=\frac{2 \times 3.14 \times 369}{60}=39 \mathrm{rad} / \mathrm{min}
$$

The rotation of armature in the magnetic field induces electromagnetic force (EMF) in the coil. The voltage equation of the circuit is therefore given as

$$
E=E_{a}+I_{a} R_{a}
$$

Multiplying both sides of equation 8 by $\mathrm{I}_{\mathrm{a}}$, we have

$$
E I_{a}=E_{a} I_{a}+I_{a}^{2} R_{a}
$$

Now $\mathrm{I}_{\mathrm{a}}{ }^{2} \mathrm{R}_{\mathrm{a}}$ is the power loss due to heating of the armature coil, therefore, the true effective mechanical power of the machine is given by,

$$
P_{m}=E_{a} I_{a}
$$

The mechanical power $\mathrm{P}_{\mathrm{m}}$ is related to the electromagnetic torque $\tau_{\mathrm{g}}$ as

$$
P_{m}=\tau_{g} \omega
$$

Where $\omega$ is speed in $\mathrm{rad} / \mathrm{min}$.

This is the developed power of the generator that is converted to electrical energy.

Now equating equation $10 \& 11$ we get,

$$
E_{a} I_{a}=\tau_{g} \omega
$$

The power delivered to the induced armature torque (counter torque) is given by equation 11

$$
P_{m}=\tau_{g} \omega
$$

$$
\begin{gathered}
\left.\left.E I_{a} \text { (electrical power }\right)=\omega_{m} \tau_{g} \text { (mechanical power }\right) \\
\therefore E I_{a}=\omega_{m} \tau_{g} \\
\text { hence, } \tau_{g}=\frac{E I_{a}}{\omega_{m}}
\end{gathered}
$$

Where; $\tau_{g}$ is the electromagnetic torque (counter torque).

$$
\therefore \tau_{g}=\frac{6.30 \times 0.87}{39}=0.14 \mathrm{Nm}
$$

Substitute $\tau_{g}$ and $\omega$ in equation 11 , we have;

$$
p_{m}=0.14 \times 39=5.46 \mathrm{Nrad} / \mathrm{min}
$$

Put $p_{m}$ in equation 6 the applied torque become;

$$
\tau_{m}=\frac{60 \times 5.46}{2 \times 3.142 \times 72}=0.75 \mathrm{Nm}
$$

The calorie burnt $\mathrm{C}\left(\mathrm{K}_{\mathrm{cal}}\right)$ by rider during the exercise period of 10 minutes was obtained as;

$$
C=\frac{M E T X k g}{h} t
$$

Where; $\mathrm{MET}=$ exercise intensity, $\mathrm{Kg}=$ rider's weight $=$ 
$71.6 \mathrm{Kg}, \mathrm{h}=$ constant time in 1 hour of energy used at rest $(60 \mathrm{~min}), \mathrm{t}=$ period of exercise in minute $=10 \mathrm{~min}$.

MET is obtain from the rider's speed using the equation;

$$
S=\frac{d_{c} X r p m_{c} X 60}{5280}
$$

Where; $S=$ rider's speed in miles per hour, $d_{c}=$ crank diameter $=41 \mathrm{~cm}$, rpm $_{c}=$ rider's pedaling speed $=72$

$$
\therefore S=\frac{41 \times 72 \times 60}{5280}=13.1 \mathrm{Mph}=21.1 \mathrm{Kph}
$$

The speed obtained is compare with the standard index number of MET for bicycling activity ${ }^{[1]}$, and the corresponding index is use as the MET of the exercise. Hence, MET of the exercise $=8$

$$
C=\frac{8 \times 71.6}{60} \times 10=95.5 K_{c a l}
$$

The efficiency of this exercise was deduced from the resistance source device at the various speed tested. Based on conservation of energy law,

$$
\text { Efficiency }=\frac{\text { power output }}{\text { power output }+ \text { losses }} X 100 \%
$$

In equation $9, I_{a}^{2} R_{a}$ is the power lost and $R_{a}$ is armature resistance

Therefore at the $72 \mathrm{rpm}_{\mathrm{c}}$, power lost,

$$
P_{m}=I_{a}^{2} R_{a}
$$

Substitute power $P_{m}$ and current $I_{a}$ into equation 17 ,

$$
R_{a}=\frac{P_{m}}{I_{a}^{2}}=\frac{5.46}{(0.87)^{2}}=7.2 \mathrm{Ohms}
$$

Power lost;

$$
P_{m}=I_{a}^{2} R_{a}=(0.87)^{2} X 7.2=5.4 \mathrm{Nm}
$$

Substitute the output power and the power lost into equation 16 we have,

$$
\text { Eff. }=\frac{5.46}{5.46+5.4} \times 100=50.3 \%
$$

The experiment was repeated at the speed of $81 \mathrm{rpm}, 89$

\begin{tabular}{|c|c|c|c|c|c|c|c|}
\hline$\tau(\mathbf{N m})$ & $R P M_{c}$ & $R P M_{r}$ & $\omega_{r}(\mathrm{rad} / \mathrm{s})$ & V (volt) & I (amp) & $\tau_{g}(\mathrm{Nm})$ & $P_{m}$ (watt) \\
\hline 0.75 & 72 & 369 & 39 & 6.3 & 0.87 & 0.14 & 5.63 \\
\hline 0.86 & 81 & 432 & 45.2 & 6.8 & 0.94 & 0.15 & 6.78 \\
\hline 1.20 & 89 & 475 & 49.7 & 7.4 & 1.42 & 0.21 & 10.4 \\
\hline 1.60 & 97 & 517 & 54.1 & 7.9 & 1.73 & 0.25 & 13.5 \\
\hline 2.30 & 105 & 560 & 58.6 & 8.2 & 1.98 & 0.28 & 16.4 \\
\hline Total calories burnt for 50 minutes & 674.1 & & & & & & \\
\hline
\end{tabular}
rpm $97 \mathrm{rpm}$ and $105 \mathrm{rpm}$ for 10 minutes each.

\section{Results and Discussion}

\begin{tabular}{|c|c|c|c|c|c|c|}
\hline$\left(\tau-\tau_{g}\right)$ & Kph & MET & $\mathrm{C}\left(\boldsymbol{K}_{c a l}\right)$ & $t(\min )$ & Charge level & Efficiency (\%) \\
\hline 0.61 & 21.1 & 8 & 95.5 & 10 & 1.02 & 50.1 \\
\hline 0.71 & 23.7 & 10 & 118.0 & 10 & 1.03 & 50.3 \\
\hline 0.99 & 26.1 & 12 & 142.0 & 10 & 1.04 & 50.6 \\
\hline 1.35 & 28.3 & 13 & 153.8 & 10 & 1.06 & 51.4 \\
\hline 2.02 & 30.7 & 14 & 165.7 & 10 & 1.08 & 51.7 \\
\hline Total calories burnt for 50 minutes & 674.1 & & & & & \\
\hline
\end{tabular}

\subsection{Results}

The data generated from the exercise work at various $\mathrm{rpm}_{\mathrm{c}}$ $(72,81,89,97$ and 105) per 10 minutes each with a rider of weight $71.6 \mathrm{~kg}$ are presented in table 1 .

Table 1. Data Generated from a Person of 71.6 Kg for each 10 Minutes of the Exercise at Various Speed.

Table 1. Continue.

\subsection{Discussion}

The design of the exercise cycle is shown in Figure 1. The designed structure was analyzed to ensure safety and avoid failure during operation.

Using equation 1 , the allowable weight on the cycle was determined. This is done to guide against excess weight on the cycle which can break down the structural frame. The bending moment on the beam is determined using equation 2 .

The evaluation of transmission chain was determined using equation 3 and 4 for chain length $\mathrm{L}$ and actual center distance $\mathrm{C}_{\mathrm{A}}$ respectively.

$\mathrm{L}$ ensures accurate matching of chain pitch with the sprocket teeth during chaining; as both are design in even number. $\mathrm{C}_{\mathrm{A}}$ determines the actual position of driving sprocket from the driven sprocket. It should be noted however that $\mathrm{L}$ and $\mathrm{C}_{\mathrm{A}}$ calculated depends on the designer's choice of length for the transmission mechanism (from driving sprocket to driven sprocket).

The constructed and assembled stationary aerobic exercise cycle with the rider is shown in Plate 1. The electric arc welding technique was applied to construct the base support. The use of this technique is to ensure a firm and rigid structure that can withstand exercise stress. Also, bolt and nut joint technique was applied to join the frame parts. This technique allow for disassembling and assembling of components in 
times of maintenance and relocation when necessary.

The speed ratio of 1: 5 for the wheel and rotor pulley was obtained using equation 5 . This ratio designed enables the rotor to rotate at the required speed (cut-in-speed) in order to generate output at low pedaling speed.

From the results of the ergometer experiment with the bicycle, the patterns of variations of the performance parameters considered were presented graphically and captured by the trend equations as indicated on the first segment of the graph with the coefficient of determination $\left(\mathrm{R}^{2}\right)$, while the direction of the slope is indicated on the second segment of the graph. Given appreciable value of $\left(\mathrm{R}^{2}\right.$ $\geq 70 \%$ ) [13], the trend equation can be used for both interpolation and extrapolation of the variable data. This has a positive implication; as there may be no need for further experiment thereby saving, time and energy.

The direction of slope captured in the second segment (Figure b) of each graph indicates whether or not the dependent and independent parameters have increasing or decreasing trend in their variability. This can be quickly checked by considering the sign and magnitude of the slope. While the sign (positive or negative) shows increasing or decreasing trend respectively, the magnitude of the slope shows the rate of the increase or decrease.

\subsubsection{Changes in Counter Torque $\left(\tau_{g}\right)$ with Applied Torque ( $\tau)$}

Figure 4a shows the variation of the counter torque $\left(\tau_{g}\right)$ with applied torque $(\tau)$. The pattern is cubic polynomial. This is captured by the cubic polynomial trend equation indicated on the graph with the coefficient of determination $\left(\mathrm{R}^{2}\right)$ of $99.64 \%$. Figure $4 \mathrm{~b}$ shows the trend (direction of slope) for the variation of counter torque with applied speed. This trend indicates that counter torque developed against the pedal is directly proportional to the applied torque and the slope is positive. The significant of this variation is that the body is exercise at higher intensity since the applied torque is increases.

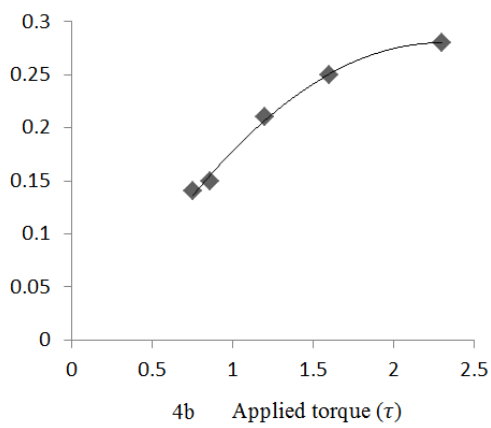

Figure 4. Changes in Counter Torque with Applied Torque.

\subsubsection{Variation of Counter Torque $\left(\tau_{g}\right)$ with $R P M_{c}$ and $\operatorname{RPM}_{r}$ (Speed)}

Figure $5 \mathrm{a}$ shows the variation of the Counter Torque $\left(\tau_{g}\right)$ with the pedaling speed $\mathrm{RPM}_{\mathrm{c}}$ (cranking) and rotor speed $\mathrm{RPM}_{\mathrm{r}}$. Each pattern of variation is captured by the logarithmic trend equation indicated on each graph with the stated coefficient of determination $\left(\mathrm{R}^{2}\right)$. The percentage of fit indicates a fit of approximately $95 \%$ for $\mathrm{rpm}_{\mathrm{c}}$ and $92 \%$ for $\mathrm{rpm}_{\mathrm{r}}$ respectively. Figure $5 \mathrm{~b}$ presents the direction of slope for the variation of counter torque with the $\mathrm{rpm}_{\mathrm{c}}$ and $\mathrm{rpm}_{\mathrm{r}}$. This linear trend (with positive slope) shows that counter torque is directly proportional to speed. The steep increase in the trend of $\mathrm{rpm}_{\mathrm{c}}$ curve indicates the rider's low pedaling speed that turns the rotor at high speed (above the cut-inspeed). It also explains the point of obtainable counter torque when human energy is used as a source of torque for the device. The direction of slope shows that counter torque increase with increase in speed. But it must be noted that as the pedaling speed $\left(\mathrm{rpm}_{\mathrm{c}}\right)$ increases from $72 \mathrm{rpm}$ to $105 \mathrm{rpm}$ (increase in intensity), the efficiency of the device does not differ distinctly from $51 \%$ (table 1 ). This indicates that a speed of $72 \mathrm{rpm}_{\mathrm{c}}$ is enough to attain appropriate counter torque of up to $50 \%$ as resistance to the exercise.

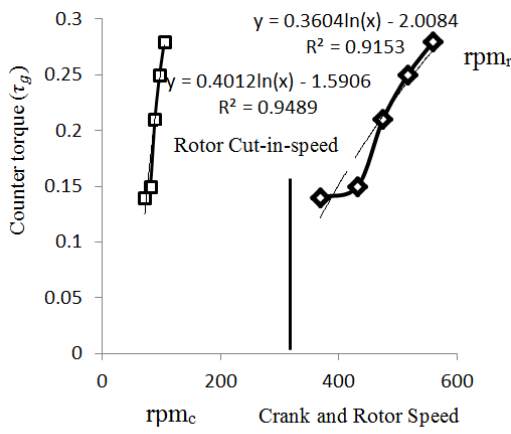

(5a)

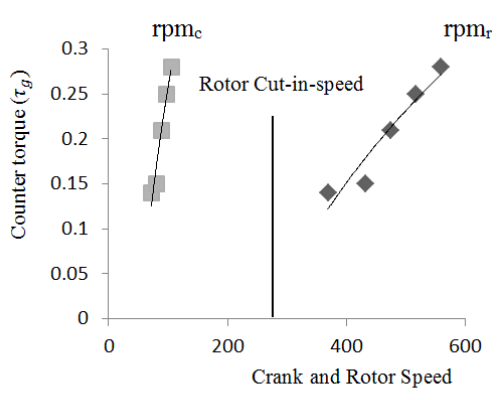

(5b) 
Figure 5. Variation of Counter Torque with the Speed.

\subsubsection{Changes in Calorie Burnt $\left(K_{\text {cal }}\right)$ with Counter Torque $\left(\tau_{g}\right)$}

Figure 6a shows the variation of the calorie burnt $\left(\mathrm{K}_{\text {cal }}\right)$ with counter torque $\left(\tau_{g}\right)$. This pattern shows that the effect of counter torque on calorie burnt requirement is a cubic polynomial. The trend equation is indicated on the graph with the coefficient of determination $\left(\mathrm{R}^{2}\right)$. This indicates a percentage fit of

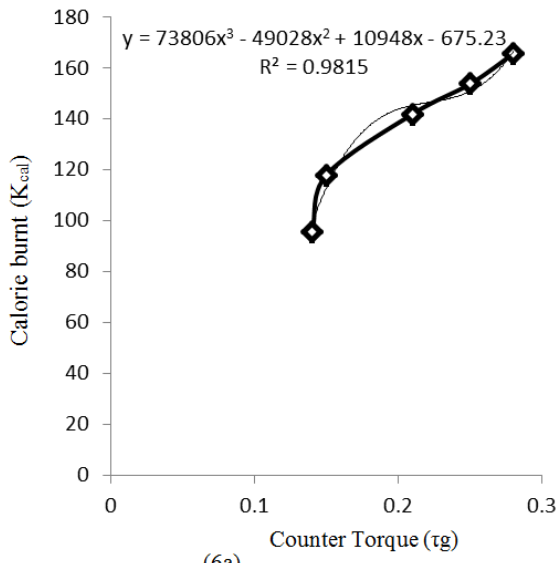

(6a) approximately $98 \%$. Figure $5 \mathrm{~b}$ shows the best fit trend for the variation of calorie burnt with counter torque. The trend (direction of slope) shown in Figure $6 \mathrm{~b}$ indicates an increase in counter torque causing an increase in the calorie burnt. This explains that calorie burnt is directly proportional to the counter torque developed on the pedal. This agrees with the standard that calorie burnt increases with exercise intensity [5].

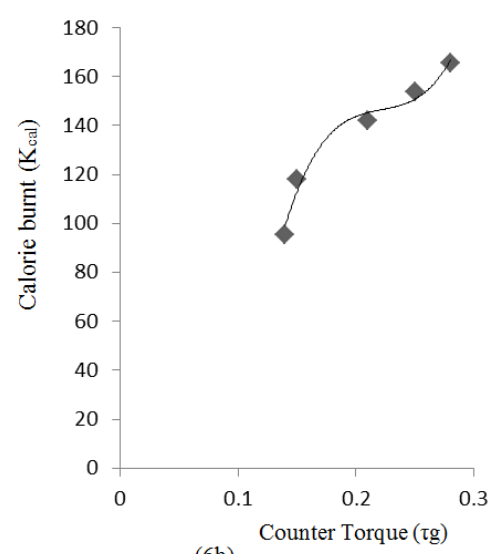

(6b)

Figure 6. Changes in Calorie Burnt with Counter Torque.

\subsubsection{Changes in Battery Charged Level with Calorie Burnt $\left(K_{\text {cal }}\right)$}

Figure 7a shows the variation of the battery charged level with varying calorie burnt $\left(\mathrm{K}_{\mathrm{cal}}\right)$. The pattern of variation is a cubic polynomial and the trend is captured by the cubic polynomial equation on the graph with the coefficient of determination $\left(\mathrm{R}^{2}\right)$. The percentage fit for this variation is approximately $98 \%$. Figure $7 \mathrm{~b}$ shows the best fit trend for the changes in battery charged level with calorie burnt. This trend shows that the variation of the battery charged level is directly proportional to calorie burnt. The result clearly shows that increase in the calorie burnt increases the charge level of the

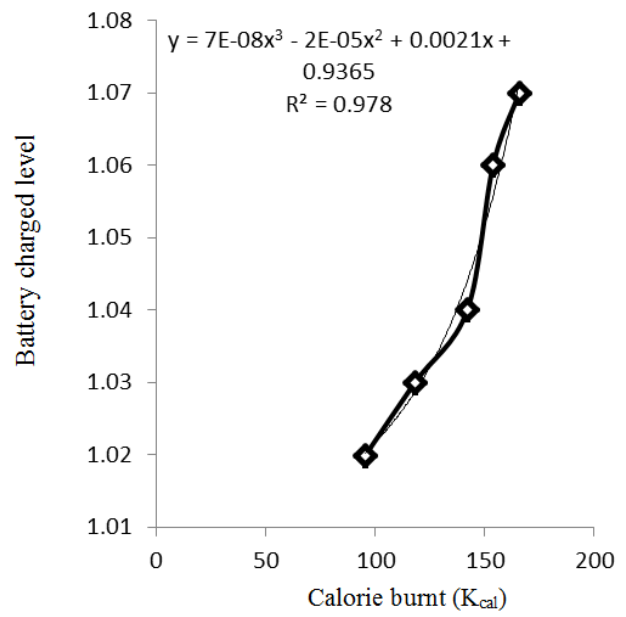

(7a) battery at constant time [10 minutes (table 1)]. This result therefore shows that increase in battery charged level depends on the exercise intensity (burning more calories by increasing the speed) but not necessarily on the duration of the exercise. It should be noted that as part of a way validating the function of this device, the charge level as measured by specific gravity of the electrolyte (table 1) conforms to the BCI standard for state of charge estimation of a battery [9]. Also note that in 10 minutes of the exercise, $5 \%$ of the battery charged level could be obtained. Going by the extrapolation of the trend equation, $60 \%$ of the total charged level of this $6 \mathrm{~V}$ battery can be obtain in 1 hour exercise period.

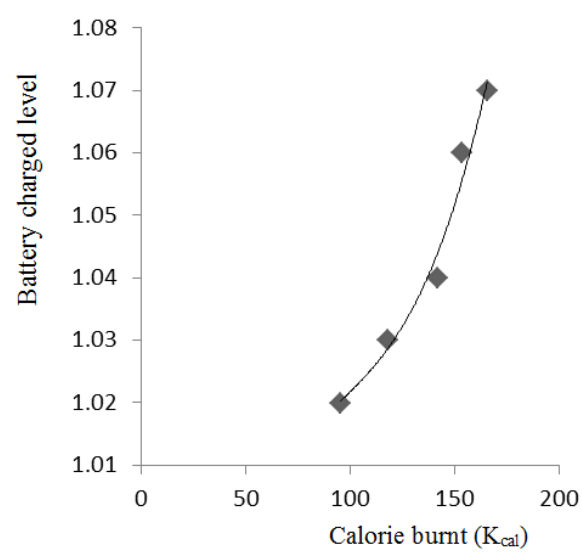

(7b)

Figure 7. Changes in Battery Charged Level with Calorie Burnt. 


\section{Conclusion}

The following conclusions were drawn from the study;

A cycle with power generator resistance as load for aerobic exercise has been successfully designed and implemented in this study. The exercise performance parameters with the cycle such as applied torque $(\tau)$, turning speed $\left(\mathrm{RPM}_{\mathrm{c}} \& \mathrm{RPM}_{\mathrm{r}}\right)$, counter torque $\left(\tau_{g}\right)$, calorie burnt $\left(\mathrm{K}_{\mathrm{cal}}\right)$ and battery charge level were identified and the relationships among them established. The relationships between the parameters are directly proportional.

The variation of the counter torque with speed is logarithmic while the other variations such as variation of counter torque with applied torque, variation of calorie burnt with counter torque and the variation of battery charge level with calorie burnt are cubic polynomial with increasing trend

The total calorie burnt of $674.1 \mathrm{~K}_{\mathrm{cal}}$ obtained from the device conforms with acceptable calorie burnt range of 70 to $1500 \mathrm{~K}_{\mathrm{cal}}$ in exercise per day [1]. Since the efficiency of the exercise at the various speeds does not vary distinctly from $51 \%$, it therefore indicate that the lowest speed of $72 \mathrm{rpm}$ is sufficient to obtained the required resistance for the exercise, hence there will be no need to pedal at higher speed to attain appropriate exercise workout.

\section{Acknowledgement}

I give glory to God Almighty and I sincerely thank Dr. A. N. Amah, senior lecturer, Department of Physics, University of Agriculture, Makurdi, Nigeria for his valuable contribution, suggestion and constant encouragement to ensure the success of this work.

\section{References}

[1] Ainsworth, B. E., Haskell, W. L., Whitt, M. C., Irwin, M. L., Swartz, A. M., Strath, S. J., O'brien, W. L., Bassett, D. R. Jr., Schmitz, K. H., Emplaincourt, P. O., Jacobs, D. R. Jr. and Leon, A. S. (2011). Compendium of Physical Activities. A Second Update of Codes and MET Values. Journal of Medicine and Science in Sports and Exercise, 43 (12): S 1575.
[2] Alexander X. (2010). Design of a New Bicycle Ergometer. Wolfson Schoolof Mechanical \& Manufacturing Engineering, Loughborough University.

[3] Asuero, A. G., Sayago, A. and Gonzalez, A. G. (2006). The CorrelationCoefficient: An Overview. Journal of Critical Review in Analytical Chemistry, 36 (8): 41-59.

[4] Carole, A., Conn, R. D. and Kravitz, L. (2014). Remarkable Calorie. Journal of Exercise \& Sports. 3 (10). 9-10.

[5] Chritianne, F., Flavia, C. Lemos M., Fabricio, C. P., Ravagnani, F., Homero P. B., Roberto C. B. (2013). Estimation of the Metabolic Equivalent (MET) of an Exercise Protocol based on Indirect Calorimetry; Journal of Exercise and Sports Sciences. 19 (2): pp 28.

[6] Fisher, J., Steele, J., Bruce-Low, S., Smith, D. (2011). Evidence Based Resistance.

[7] Gibson, T. (2011). Turning Sweat into Watts. Spectrum, IEEE, 48 (7): $50-55$.

[8] Hamilton, C. (2010). Bicycle Trainer with Variable Resistance to Pedalling. US patent, US0062908A1.

[9] Jorgustine, K. (2015). Battery State of Charge for Voltage and Specific Gravity. www.modernsurvivalblog.com.

[10] Livermore, C., Henrik S., James W. Jr. and Simona S. (2006). Mechanics and Materials. John Willey and Son Inc., pp 43. ISBN 1-523-64417-7.

[11] McColligan, M. and Henderson, N. (2009). Blackburn Trainers White Paper Abstract (online), www.blackburndesign.com/blackburn techTrainers pdf.

[12] Michael, R. (2013). Resistance Training for Health and Fitness; America College of Sport Medicine, www.acsm.org.

[13] William, D. M., Frank, I. K., Victoria L. K. (2006). Essentials of Exercise Physiology. Lippincott Williams \& wikkins. P 204 ISBN 978-0-7827-4991-6.

[14] Wilson, D. G., Jim, P. (2004). Bicycling Science. Massachusetts Institute of Technology, 343(5): ISBN 0-26223111-5. Training Recommendation. Journal of Medicina Sportiva. 15 (3): 147-162. 